\title{
EM BUSCA DE ELEMENTOS PARA UMA HISTÓRIA DA LITERATURA CONTEMPORÂNEA: UM OLHAR SOBRE A ESCRITA DE SI EM DIÁRIO DA QUEDA, DE MICHEL LAUB
}

\author{
Jandré Corrêa Batista \\ Michael Azevedo Kuhn ${ }^{* *}$ \\ Universidade Federal de Pelotas
}

\begin{abstract}
Resumo: O presente trabalho pretende contribuir sobre a compreensão das características da literatura brasileira contemporânea, a partir da obra Diário da Queda, de Michel Laub (2011). Diário da Queda conta o episódio de um menino não-judeu (João), de 13 anos, que sofre um "acidente", narrado anos depois pelo seu principal causador (neto de um judeu sobrevivente do campo de concentração de Auschwitz). As implicações da "queda" de João desencadeiam no narrador-protagonista uma série de questionamentos sobre identidade, memória e intolerância. A partir de tal produção, traçar-se-á uma breve análise sobre questões relativas à sua construção sintática peculiar e ao formato de diário. Além disso, estão em foco questões como o enfraquecimento do narrador e o enxugamento da narrativa. Para refletir, portanto, sobre as características estruturais da obra de Michel Laub, serão utilizados para balizar a análise, principalmente, os seguintes autores: Moriconi (1992), Süssekind (2000), Bauman (2001) e Lipovestsky e Serroy (2009), Castro (2009).
\end{abstract}

Palavras-chave: Literatura contemporânea. Diário da Queda. História da literatura.

\footnotetext{
* Doutorando em Comunicação e Informação pela Universidade Federal do Rio Grande do Sul (UFRGS), mestre em Comunicação Social pela Pontifícia Universidade Católica do Rio Grande do Sul (PUCRS), licenciado em Letras pela Universidade Federal de Pelotas (UFPel) e bacharel em Jornalismo pela Universidade Católica de Pelotas (UCPel).

${ }^{* *}$ Licenciado em Letras pela Universidade Federal de Pelotas (UFPel).
} 


\section{Introdução}

O presente trabalho pretende contribuir sobre a compreensão das características da literatura brasileira ${ }^{1}$ contemporânea, utilizando-se, para tanto, da obra "Diário da Queda", de Michel Laub. Como possível representante emblemático da "pósmodernidade" literária, traçar-se-á uma breve análise sobre os aspectos estruturais da obra em questão.

Por meio de uma prosa repleta de lirismo angustiante e memorialístico, Diário da queda conta o episódio de um menino não-judeu (João), de 13 anos, que sofre um "acidente", narrado anos depois pelo seu principal causador (neto de um judeu sobrevivente de Auschwitz). As implicações da "queda" de João desencadeiam no narrador-protagonista uma série de questionamentos sobre identidade, memória e intolerância. Abordando a relação entre pai e filho de três gerações de uma família judia e como essas relações se estabelecem no passado, presente e futuro, Laub consegue, com a colaboração da Bolsa Funarte de Criação Literária, construir um proeminente romance contemporâneo. Entre as suas premiações, Diário da queda ganhou o Prêmio Brasília de Literatura e o Prêmio Bravo/Bradesco como melhor romance.

Primeiramente, colocar-se-ão em pauta as questões referentes ao exercício da crítica, problematizando a necessidade do distanciamento acerca do espaço-tempo de construção da história literária contemporânea, com base em Moriconi (1992). Em seguida, apresentar-se-ão breves considerações sobre a obra de Michel Laub, descrevendo e replicando seu conteúdo, para então se traçar apontamentos preliminares sobre as características da literatura contemporânea. A discussão é balizada por reflexões sobre o contexto em que tal produção literária se insere, descrito por Bauman (2001), Lipovetsky e Serroy (2009), entre outros.

Acerca das características da obra, reflete-se sobre a construção sintática peculiar de Laub, repleta de orações intercaladas, alternativas e aditivas; sobre o enredo em forma de verbetes, notas numeradas divididas em capítulos, o que revela

\footnotetext{
${ }^{1}$ Não se entra na discussão sobre o que seria uma literatura brasileira, nem se aquela escrita em língua portuguesa ou escrita no território nacional, conforme já anunciava Machado de Assis (1999). Para esse o autor, a idéia de territorialidade não é fundamental para a manifestação da nacionalidade literária. Os assuntos "locais" não fazem brasileira uma literatura. Hamlet, Otelo, Romeu e Julieta, por exemplo, não se limitam à história inglesa. Manifestam, em vez disso, um "gênio universal". "Não há duvida de que uma literatura, sobretudo uma literatura nascente, deve principalmente alimentar-se dos assuntos que lhe oferece a sua região; mas não estabeleçamos doutrinas tão absolutas que a empobreçam. O que se deve exigir, antes de tudo, é certo sentimento íntimo, que o torno homem do seu tempo e do seu país, quando trate de assuntos remotos no tempo e no espaço" (ASSIS, 1999, p. 17-18)
} 
possivelmente um processo de enxugamento da narrativa (SÜSSEKIND, 2000); e sobre a fragilização do narrador, cada vez mais limitado - e, por consequência verossímil. Em Diário da Queda, o narrador-protagonista não é onisciente, não consegue desvendar o outro; sequer a si mesmo.

Por meio de um texto enxuto, de tom forte, o leitor é convidado a vestir a pele de um filho que lê o que o pai escreve, tentando compreender as lacunas deixadas pelo narrador. O texto apresenta-se numa ordem não-linear, com digressões e associações entre três personagens protagonistas que parecem ser um só: a tríade filho-pai-avô. Busca-se, a partir dos elementos que aqui serão apresentados, contribuir para a discussão sobre a história da literatura contemporânea.

\section{Acerca do olhar}

Conforme nos coloca Moriconi (1992), o esforço de entender a história da literatura recente apresenta ao pesquisador um dos maiores impasses do exercício da crítica. Defronta-se com um problema que traduz, muitas vezes, um dos maiores dilemas da ciência. A aproximação ao objeto favorece ou prejudica a plena compreensão dos fenômenos? Por um lado, a resposta é negativa. Absorvido nos acontecimentos contemporâneos ao pesquisador, não existiriam ângulos confortáveis, com suficiente distância crítica, para a emissão objetiva e isenta de juízos de valor.

A crítica da crítica, no entanto, sustenta que, independentemente do distanciamento, as produções literárias são vítimas da "parcialidade" comum a todo discurso acadêmico preocupado em categorizar a literatura no tempo e no espaço. "A arbitrariedade redutora e normativa - de qualquer discurso estético-histórico enraíza-se num abismo ontológico que nenhum distanciamento analítico pode superar" (MORICONI, 1992, p.17).

Para esse autor, não se nega, no entanto, a importância da formação de cânones literários para a sobrevivência de qualquer língua com pretensões de manifestar-se culturalmente no contexto global. A literatura pedagógica, por visar a categorização de produções no tempo e no espaço, possui o seu valor no sentido de colaborar à manutenção das produções literárias numa determinada língua. A principal contribuição é o fornecimento de uma leitura-padrão, na intenção de fixar as coordenadas de uma leitura abrangente, pedagógica, capaz de formar uma comunidade de leitores. Somente 
por meio dessa comunidade de leitores é que a obra literária poderá alcançar o status de canônica.

No entanto, o olhar lançado ao passado é capaz de reduzir a obra literária. A crítica pedagógica suprime a maior qualidade da literatura: a impermanência no tempo e no espaço. "A crítica é traidora quando tenta capturar o poema nas malhas de uma relação monogâmica, exclusiva, metodicamente fechada" (MORICONI, 1992, p.19). Segundo o autor, o texto é uma formação híbrida. Ainda que supostamente manifeste uma determinada estética, apenas o leitor atento poderá ir além, percebendo "resíduos e marcas de outras estéticas" (MORICONI, 1992, p.19), a partir da "possibilidade de intervenção criativa por parte de algum leitor com sua leitura singular, inesperada e aventureira” (MORICONI, 1992, p. 18).

Daí o choque de interesses. A glória do poema é libertar-se de seu contexto
original para poder renascer em qualquer outro. Em contraste, a glória da
história da poesia, o que a realiza enquanto prática disciplinar, é situar o
poema em seu "próprio" contexto. Por isso, não há como tergiversar. A
história da poesia importa menos como contribuição à leitura do poema ou da
obra do poeta em sua singularidade do que como a contribuição a outra
historia (MORICONI, 1992, p. 20 )

A crítica, assim, é enganadora pela injustiça da disciplinarização do texto literário. Essa incoerência entre texto e crítica torna-se maior se considerarmos o esforço historiográfico, ainda mais quando está clara a pretensão de uma classificação histórica a partir de rótulos generalizadores. O que é ainda pior: segundo Moriconi (1992), percebe-se que as produções realmente aplicáveis às categorias estéticotemporais são, muitas vezes, as mais "medíocres" de cada período. A estética classificatória nunca esgota a realidade do poema, não devendo, assim, o texto ser apontado como um instrumento de descrição estática.

Segundo essa perspectiva, por não serem os textos instrumentos estáticos, entende-se que o deslocamento de tempo em relação a essas produções é irrelevante para a percepção e compreensão de suas características fundamentais. Talvez a aproximação, a absorção ao contexto, seja mais importante para a percepção plena dos fenômenos. Para Moriconi (1992), fazer uma história da literatura contemporânea significa perceber as distinções em relação aos fatos antecedentes, o que não quer dizer que o distanciamento de tempo facilite ou prejudique o trabalho. Independentemente do distanciamento cronológico da produção literária, há períodos mais fáceis e outros mais difíceis de identificar as densidades fundamentais das obras literárias. 


\section{Diário da Queda}

O romance "Diário da Queda" é dividido em pequenos capítulos, que são dispostos em unidades maiores. Essas unidades repetem-se, voltando ao ponto de partida, num certo vai-e-vem de informações que podem confundir o leitor, mas não a ponto de desestruturá-lo em sua leitura. O romance é estruturado em pequenos textos em formato de verbetes, narrados pelo personagem principal (sem nome).

Três grandes blocos são perceptíveis: Coisas que sei sobre o meu avô, Coisas que sei sobre o meu pai, Coisas que sei sobre mim. Em cada uma dessas subpartes, pode-se perceber um longo período de tempo transcorrido. A passagem do tempo abarca o crescimento e o amadurecimento do personagem-narrador, mostrando o destino das personagens por ele citadas (todas sem nome, exceto João).

Das muitas possíveis 'quedas' simbólicas que se podem extrair da obra de Michel Laub, uma delas é explícita no texto: um menino de então 13 anos, chamado João, machuca-se seriamente em sua festa de aniversário. Tendo estudado em uma escola de judeus, o protagonista-narrador conhece João, um menino pobre, sustentado com muitas dificuldades por seu pai. Por não ser judeu, João sofre preconceito dos colegas; fazem-no passar por diversos abusos, como, por exemplo, comer areia. Amedrontam-no e agridem-no fisicamente sem que ele reaja a tudo isso. Mesmo assim, João decide comemorar o seu aniversário com todos os colegas da sétima série, dentre eles, o personagem protagonista do romance.

\footnotetext{
(...) e eu nunca mais veria nele o desdobramento do que tinha feito por tanto tempo até acabar ali, a escola, o recreio, as escadas e o pátio e o muro onde João sentava para fazer o lanche, o sanduíche jogado longe e João enterrado e eu me deixando levar com os outros, repetindo os versos, a cadência, todos juntos e ao mesmo tempo, a música que você canta porque é só o que pode e saber aos treze anos: come areia, come areia, come areia, gói filho de uma puta. $^{2}$ (LAUB, 2011, p.22)
}

Num ritual comum entre os meninos judeus, João seria lançado treze vezes para o alto. Na décima terceira, o menino que segurasse o pescoço, daria um passo para trás. O plano foi muito bem planejado pelos colegas dias antes da festa. Enquanto faziam a tradicional celebração judaica, seus colegas deixaram-no encontrar o chão, propositadamente.

\footnotetext{
${ }^{2}$ Grifos Originais
} 
A queda acaba revelando um lado que o personagem-narrador não conhecia sobre si. O personagem exibe a sua frieza e falta de controle, justamente a mesma forma de manifestação da intolerância que tanto desprezara (contra um não-judeu), ao ouvir o pai falar sobre as memórias do avô, um sobrevivente do Holocausto. O episódio soa para o personagem-narrador como um crime, algo tão sério que não poderia passar impune.

O fato desencadeia a reflexão do personagem-narrador sobre um dos temas mais caros ao livro: Auschwitz e a memória do Holocausto. A motivação por deixar o colega, o único não-judeu, sofrer a queda permite ao personagem-narrador questionar-se sobre a memória do extermínio e os efeitos da intolerância passados de geração a geração. As consequências desse acontecimento provocam sérias mudanças na vida do narrador-personagem. A adolescência difícil, o casamento em crise, os rumos de três gerações de sua família são marcados pela memória da intolerância.

Seu avô, um dos poucos sobreviventes, carregara profundas marcas dos campos de concentração, chegando a enlouquecer. Vira-se, até os seus últimos dias, absorvido na escritura de um "diário-dicionário", excessivamente carregado de suas incoerências e visões "idealizadas" de mundo. Nos verbetes, o avô revela suas percepções preconceituosas e suas inquietudes (preocupado com a higiene dos ambientes - possivelmente em contraste às condições dos campos de concentração).

\footnotetext{
16. Esposa - pessoa que se encarrega das prendas domésticas, cuidando para que sejam empregados procedimentos os mais rigorosos de higiene na casa e também para que no dia do marido não existam perturbações quando ele deseja ficar sozinho (LAUB, 2011, p.31)

21. Hospital - lugar com médicos pacienciosos que explicam à mulher grávida os riscos da gravidez que são baixos e os riscos da operação de cesariana que são baixos também, e os riscos de infecção depois do parto que são inexistentes dados os procedimentos os mais rigorosos de higiene no edifício, que se estendem aos banheiros onde corre água quente e privadas que são lavadas em hora em hora, e aos funcionários que aplicam durante o dia procedimentos os mais rigorosos de higiene tais como uso de desinfetantes e métodos de esterilização, quarentena também. No hospital não há problemas que possam perturbar a paz do marido da esposa grávida, cujo filho irá selar a continuidade e doação amorosa dos dois (...) (LAUB, 2011, p. 46)
}

A partir do acontecimento, a queda, o personagem-narrador aproxima-se ainda mais de João. A culpa inicial por sua atitude fez com que o personagem-narrador passasse a tentar amenizar as suas ações. Ele oferece a ajuda necessária para suprir os meses de aula e provas que João havia perdido por conta de seu afastamento. A 
aproximação, repleta de remorso, foi o principal impulso para que os dois começassem a ser amigos.

Difícil dizer por que me tornei amigo de João. Essas coisas não acontecem porque você tem pena de alguém, ou porque passou meses torturado com a hipótese de quase ter destruído essa pessoa, embora isso possa ajudar no começo, ao menos como impulso no primeiro esforço de aproximação. Não fosse esse incômodo inicial eu não teria me oferecido para ajudá-los com os estudos, não fossem as tardes na minha casa nós não teríamos convivido por tanto tempo (LAUB, 2011, p. 35)

A angústia era tanta que o personagem-narrador acabou confessando à coordenadora da escola que não havia sido um simples acidente, mas sim um conjunto planejado de ações. A revelação gerou o ódio dos colegas envolvidos, que foram expulsos da instituição, enquanto o protagonista apenas assinava uma advertência.

A confissão contribuiu para que os dois meninos trocassem de educandário. A mudança ocasionou um conflito intenso entre o personagem-narrador (então com catorze anos) e o seu pai. O motivo: as memórias deste sobre a experiência do avô no campo de concentração. O episódio mostra um desespero do personagem-narrador, tentando, desesperadamente, afastar-se da memória de seu avô. A intolerância registrada em Auschwitz reverberava em suas ações: o sofrimento imposto aos judeus replica inversamente, mesmo depois de duas gerações, num contexto escolar.

O protagonista de Laub busca desvencilhar-se de seu passado, de seu avô, da intolerância, do trauma, do sufoco que é Auwsvitz. No entanto, isso não acontece. A memória lhe é tão cara a ponto de formar a sua identidade enquanto judeu e de fazê-lo resguardar, também num "Diário", a memória de sua família.

Evidencia-se, assim, ligação existente entre filho, pai e avô. Mais do que isso, a relação existente entre cada um deles (entre pai e filho). Cada geração carrega marcas da geração anterior. Os medos, as angústias e os receios são passados de pai para filho, refletidos em cada atitude, cada sensação, cada pensamento. Além disso, tal ideia é corroborada ao término do romance: o leitor coloca-se no lugar do filho do personagemnarrador; o protagonista, em seu diário (o livro Diário da Queda) dirige-se ao leitor (filho), tentando reconstruir a sua vida e os seus anseios, assim como fizeram os outros personagens.

A influência do trauma do Holocausto é tão grande que o narrador-personagem faz questão de usar, repetidas vezes, a palavra Auschwitz. A repetição no texto mostra o grau de envolvimento das personagens com o tema, mesmo quem não tenham tido 
relação direta com o episódio (ao contrário do caso do avô, que experienciou o mais emblemático dos campos nazistas).

24. Aos catorze anos é quase impossível você acordar às sete da manhã, a casa toda em silêncio e você sem mais nem menos saindo da cama e indo ao banheiro e à cozinha pegar algo na geladeira, isso não faz sentido se você não for acordado por um sonho ou pressentimento ou barulho, e todas as vezes em que meu pai falou de Auschwitz acho que ele lembrou exatamente desse dia, meu pai abrindo os olhos (Auschwitz) e abrindo a porta do quarto (Auschwitz) e hesitando ao lembrar do escritório (Auschwitz) onde o meu avô tinha passado a noite e todas as noites desde que viu derrotado por suas lembranças.

25. Aos catorze anos eu bebi uísque sozinho no quarto porque também comecei a me ver diante dessas lembranças. Elas estavam nos desenhos de Hitler, nos bilhetes sobre a mãe de João, na certeza de que por causa deles eu nunca mais poderia ser amigo de João, e eu mudaria de escola e eu conheceria outras pessoas e seguiria a vida sem nunca mais saber o que foi feito de João, se ele está vivo (Auschwitz), se continua em Porto Alegre (Auschwitz), se virou médico ou advogado ou cobrador de ônibus (Auschwitz, se alguma vez nesses mais de vinte anos percebeu que desenhar Auschwitz era o mesmo que desenhar a doença da mãe dele, porque Auschwitz era para o meu avô o que a doença foi para a mãe dele, e a história do meu avô sempre foi a mesma história da mãe dele. (LAUB, 2011, p. 103)

No período escolar, a situação envolvendo a queda de João (e os preconceitos que este sofrera por ser pobre e não-judeu em uma escola de quase totalidade judia) acaba invertendo-se. O personagem-narrador, antes agressor, torna-se vítima. $\mathrm{Na}$ nova escola, desenhos produzidos por João passam a insinuar aspectos relativos ao Holocausto. Lá, João, por ser judeu, passa a ser minoria.

Laub constrói seu protagonista no período da adolescência. É a idade de transição, em que o menino passa a sofrer tanto mudanças físicas quanto psicológicas, fundamentais para seu processo de amadurecimento e reconhecimento da realidade circundante. Nessa faixa etária, tanto o personagem-narrador quanto o seu pai não obtiveram a atenção necessária. $\mathrm{O}$ avô ficara perdido em seus anseios e angústias, negligenciando a família. Com esse panorama familiar, o narrador-personagem também se vê perdido em relação ao episódio no aniversário de João. Tenta ter a atenção do pai, que por sua vez, está mergulhado nas tristes lembranças do passado. Pai e filho passam por grandes traumas, ambos com catorze anos, reverberando o sofrimento causado pela morte trágica do avô do menino.

Contar uma vida desde os catorze anos, repito, é aceitar que fatos gratuitos ou devidos a circunstâncias que fogem à lógica possam ser agrupados em relações de causa e efeito. (LAUB, 2011, p. 126) 
Todos os conflitos familiares retratados começam com o avô, por meio de seus verbetes e de sua experiência pós-tragédia. $O$ fato é que ele nunca consegue se restabelecer, apesar de tentar reconstruir a família que perdera, casando e tendo um filho (pai do narrador-protagonista). Os seus escritos, elaborados quando estava trancado dentro do seu escritório, acabam afastando-o da sua realidade. Porém, Auschwitz não saia de sua cabeça; sua postura acabou por refletir profundamente na vida do filho (que "perdera" o pai antes mesmo de este cometer suicídio).

O pai tenta reconstruir o passado do avô do narrador por meio dos fragmentos prolixos dos dezesseis cadernos traduzidos. Logo que se descobre portador do mal de Alzheimer, a mesma idéia parece tomar conta de si: a construção de sua identidade enquanto judeu, também por meio de um diário, contendo suas lembranças, para que o filho (o narrador) o compreenda e construa a sua identidade. Diferentemente das memórias do avô, o diferencial dessas lembranças é que elas são repletas de subjetividade, de sentimentos, longe da frieza dos verbetes do avô. A ideia do registro do pai é justamente que o filho fique sabendo dos seus sentimentos mais remotos, dos seus medos aprisionados, preservando lembranças que são apagadas dia após dia, como consequência da doença degenerativa que afeta a sua memória.

$\mathrm{Na}$ escritura de seu próprio Diário (o livro Diário da Queda), o narradorpersonagem, a exemplo de seu pai, vai reconstruindo também a história de vida do avô e do pai, acrescentando informações sobre si (como o fato de se tornar alcoólatra); construindo um memorial, uma espécie de árvore memorialístico-genealógica para o seu futuro filho, fruto do terceiro casamento conturbado. O leitor é levado a ocupar o papel desse filho, que está prestes a nascer.

\begin{abstract}
Eu imagino o meu pai com catorze, dezesseis, dezoito anos, os dias divididos entre a escola e a loja, os jantares em silêncio com a minha avó, a faculdade de administração, meia dúzia de amigos, meia dúzia de namoradas e o baile onde ele conheceu a minha mãe, e é impossível que na aproximação com a minha mãe não houvesse a sombra daquela manhã de domingo, não só no que qualquer um concluiria a respeito, a inevitabilidade daquele desfecho diante da vida que meu avô teve, diante das lembranças do meu avô, e desculpem se preciso voltar mais uma vez a este assunto, e dizer mais uma vez essa palavra, e evocar mais uma vez o significado dela, Auschwitz, mas também em relação ao futuro (LAUB, 2011, p. 117).
\end{abstract}

\title{
Um breve olhar sobre as características
}

A narrativa de Laub tem um ritmo acelerado. O autor escolhe a estrutura da obra dentro da idéia de dicionário sem datação cronológica. A narrativa não é linear, 
não é cronológica. O interlocutor é, possivelmente, também o próprio narrador, dentro da idéia de que, na escritura de um diário, escreve-se para si.

Ricoeur (2006) afirma que “(...) a finalidade de toda forma narrativa é contribuir à compreensão de si”. Por meio do modelo de diário, o personagem conta fatos importantes sobre a sua vida; fatos esses que são essenciais para o entendimento do enredo, do entrelaçamento existente entre pai, filho e avô. O passado manifesta-se no presente e, possivelmente, no futuro (o legado deixado ao filho do narrador). $\mathrm{O}$ personagem-narrador é um pouco de seu avô e seu pai.

Pelas escolhas estruturais de Laub, observa-se um processo narrativo de enxugamento. O formato de diário e registro de memórias permite que o encadeamento do texto não seja tão truncado. O formato em "notas", todas numeradas, traz um ritmo de relato que torna acelerada a leitura.

Süssekind (2000) observa, como característica da literatura brasileira contemporânea, o enxugamento da narrativa; elemento perceptível, por exemplo, na redução crescente das miniestórias de Dalton Trevisan (vencedor da $24^{\mathrm{a}}$ edição do Prêmio Camões, o mais importante da literatura lusófona). Em Diário da Queda, a miniaturização pode ser percebida pela escolha do autor em organizar o seu livro em pequenas partes, notas e outros verbetes. Juntos, esses segmentos formam o todo da narrativa.

\footnotetext{
Talvez se possa observar a literatura brasileira produzida nos últimos anos não segundo o consenso negativo dos balanços de fim de década, mas sob a perspectiva tripla de uma crise de escala, de uma tensão enunciativa e de uma geminação entre econômico e cultural que, se não exclusivas do período, por conta de intensificação e disseminação generalizadas, se converteriam em premissas dominantes da experiência literária contemporânea. Chama a atenção, nesse sentido, sobretudo no último decênio, uma espécie de variação sistemática de escala, manifesta tanto em exercícios, por vezes paradoxalmente concomitantes, de expansão e compressão, quanto em movimentos de narrativização da lírica, de um lado, e de miniaturização narrativa, de outro (SÜSSEKIND, 2000, p.1).
}

O enxugamento das narrativas está alinhado, possivelmente, às perspectivas contemporâneas do leitor-consumidor sobre as suas atuais percepções de tempo e de espaço. Projetos autorais ("não-comerciais") como a série "O Tempo e o Vento", de Érico Veríssimo tendem, por conta de sua extensão, a não mais emergir no contexto contemporâneo. A redução do texto é capaz, assim, de refletir a fluidez dos tempos modernos (líquidos) ${ }^{3}$. A rapidez dos fluxos da hipermodernidade (LIPOVETSKY e

\footnotetext{
${ }^{3}$ Cf. Bauman (2000)
} 
SERROY, 2009) faz da passagem do tempo algo por demais precioso. A partir da velocidade do acesso à informação, das novas relações do tempo e do espaço, a escolha por uma narrativa não-linear, segmentada, torna-se possivelmente mais atrativa às exigências de leitores cada vez mais "hipermodernos".

Se a modernidade sólida punha a duração eterna como principal motivo e princípio da ação, a modernidade 'fluida' não tem função para a duração eterna. O 'curto prazo' substitui o 'longo prazo' e fez da instantaneidade seu ideal último (BAUMAN, 2001).

Outra característica marcante é a perda do sentido, a inconsistência da modernidade nos tempos contemporâneos, registrados em Bauman (2001). Tomam-se o lugar das bases, os líquidos. Manifestam-se a descrença nas instituições, o descrédito à política, a perda da rigidez dos valores. Esses elementos podem ser possivelmente percebidos em Diário da Queda. O filho é o narrador e ao mesmo tempo o narratário (e também não é). Ele conta a sua história, repete-se conforme os seus fluxos de consciência, como se admite no trecho abaixo:

\footnotetext{
Desculpem se repito que Auschwitz ajuda a justificar o que o meu avô fez. Se é mais fácil culpar Auschwitz do que aceitar o que o meu avô fez. Se é mais cômodo continuar listando os horrores de Auschwitz, e tenho a impressão de que todos estão um pouco cansados disso, o número de sobreviventes de Auschwitz que acabaram exatamente como Primo Levi e o meu avô (...) Em trinta anos será quase impossível achar um ex-prisioneiro de Auschwitz (...) Em sessenta anos será muito difícil achar um filho de ex-prisioneiro de Auschwitz (...) Em três ou quatro gerações o nome Auschwitz terá a mesma importância que hoje tem nomes como Majdanek, Sobibor, Belzec (LAUB, 2011, 117-118)
}

A idéia de diário - escrever para si - toma para o narrador as bases da ideia de sistema literário de Antônio Candido. Para explicar o processo de formação da literatura brasileira, Candido (1961) propõe o conceito de sistema literário, tendo como base a definição de uma estrutura básica presente em obras de literatura propriamente ditas. Segundo o autor, há três categorias básicas importantes que delimitam um sistema de obras ligadas por denominadores comuns. Internamente, língua, temas e imagens devem são partilhados; externamente, é preciso haver um conjunto de produtores conscientes de seu papel (autor), um conjunto de receptores (leitor), e, finalmente, um mecanismo transmissor (o livro).

Em Diário da Queda, o narrador é, ao mesmo tempo, autor, leitor e obra. É o protagonista também a obra (a sua memória), o autor (quem escreve) e o leitor (para quem se escreve). O protagonista é o seu pai e também o seu avô, conectados pela 
experiência em Auwsvitz. O diário apresenta-se também no sentido de resgate da própria memória para o filho do narrador (a possível continuação geracional da memória da experiência do Holocausto). Talvez por essa razão, nenhum dos três personagens (pai, avô e filho) tenha um nome anunciado; é como se todos fossem um só.

A escolha de narração (em $1^{\mathrm{a}}$ pessoa) dialoga com as características contemporâneas. Como os líquidos da modernidade, nada é absoluto, rígido o suficiente que justifique a memória com ares de história. Esse caos circundante também é perceptível pela recorrência das conjunções aditivas (e... e...), das conjunções alternativas (ou... ou...), orações intercaladas e notas explicativas, recursos utilizados expressivamente ao longo de toda obra, resultando, muitas vezes, numa leitura pontualmente densa. Na perspectiva do leitor, perde-se a linha de raciocínio. Tais características beiram novamente o fluxo de consciência, tornam o texto tão complexo, desestruturado e caótico quanto a memória de quem se propõe a contar a história.

\begin{abstract}
Auschwitz e um suicídio e eu quase agredindo a única pessoa por quem me apaixonei, Auschwitz e um suicídio e eu quase dando as costas para quem eu me apaixonei, Auschwitz e João e meu avô e o meu pai e eu quase jogando fora o que essa pessoa a mim, a sorte e o milagre que foi um dia ter cruzado com ela, e quando falo em milagre considero o fato de que apesar de tudo ela não foi embora, e apesar de tudo ela está grávida, e apesar de tudo falta muito pouco para que o ciclo inteiro se complete (LAUB, 2011, p. 39)
\end{abstract}

O protagonista-narrador não é onisciente (o narrador não conhece internamente as suas personagens, como o típico narrador do Romantismo, por exemplo); o texto é produzido em primeira pessoa, tornando, assim, o narrador tão desconfiável quanto a memória que ele visa preservar em seu "Diário". Admite-se a fragilidade do narrador; assume-se que não existe uma única verdade nem uma única versão da história de vida de cada um. Diário da Queda investe nessa subjetividade da narrativa, pois, por meio de um texto fragmentado e de personagens que não são modelos de conduta, o leitor questiona-se sobre si, sobre seus erros e suas relações familiares.

Castro $(2009$, p. 5) revela que

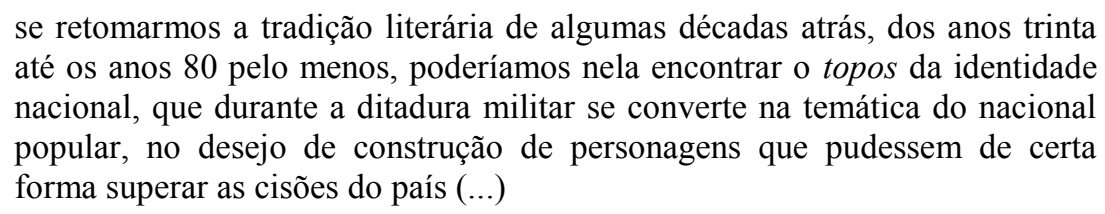

Se levarmos em conta o atual cenário da literatura contemporânea, pode-se argumentar que não há mais espaço para a construção de uma identidade coletiva (que não há mais um projeto de nação). Discute-se hoje a identidade do sujeito, cada vez 
mais fragmentada e constituída artificialmente. À medida que os sujeitos lutam por singularização, mais se tornam semelhantes uns aos outros (SIBILIA, 2008).

(...) a busca de uma estética pós-modernista simultaneamente repete e transgride o modernismo enquanto totalidade. A banalização do poético pelo modernismo tem por meta destruir o sublime clássico e romântico, mas acaba por instituir o sublime moderno - abstrato, hermético, abissal, auto-reflexivo (...) (MORICONI, 1992, p. 30-31)

O "sublime moderno", dentro da busca por uma estética pós-modernista, é encontrada principalmente pelo caráter auto-reflexivo do narrador-protagonista: um homem revisitando o seu passado. É a memória que permite registrar as sensações humanas, revelando cada fraqueza, cada detalhe angustiante de sua vida. As memórias em Diário da Queda têm o objetivo de construção, ou melhor, de reconstrução da identidade de cada relação pai-filho. O personagem-narrador mexe no passado, tentando reconstruir uma nova identidade para a sua família, livre de toda a carga, ao mesmo tempo em que passa a perceber ser impossível livrar-se dela. O resultado é esse todo tão emaranhado, subjetivo, abstrato e repleto de contrariedades e interpretações; de como as experiências dos pais acabam afetando a dos filhos, numa relação de causa-efeito tão grande e sistemática, capaz de causar tantas angústias.

\section{Considerações finais}

No presente trabalho, buscou-se apresentar uma breve análise da obra "Diário da Queda”, de Michel Laub. A partir de tal produção, a proposta em tela visou colaborar para a compreensão das características da literatura brasileira contemporânea. Para tanto, em um primeiro momento, partiu-se das discussões acerca do distanciamento da crítica em relação ao período histórico em análise.

Defendeu-se que o distanciamento em relação ao fenômeno não é necessariamente prejudicial. Em vez disso, pode colaborar, em razão da proximidade cronológica, para o reconhecimento das densidades literárias do período (contemporaneidade). O texto, independentemente do afastamento da crítica, transcende ao tempo e ao espaço.

Em seguida, traçaram-se breves considerações sobre a obra de Michel Laub, Diário da Queda, para então se apresentar uma leitura sobre as características da literatura contemporânea. Associaram-se, assim, algumas características estruturais da obra ao contexto em que ela se insere. Discutiu-se, brevemente, sobre o processo de 
enxugamento e fragmentação da narrativa, sobre o enfraquecimento da figura do narrador (em $1^{a}$ pessoa) e sobre a estruturação da obra em diário e sua construção sintática particular.

O trabalho não se esgota nesta leitura pormenorizada; é apenas um início de discussão. A obra de Laub permite diversas leituras a respeito da natureza humana, das experiências e fugas pessoais, narradas por meio de diários.

\section{Referências}

ASSIS, Machado. Instinto de Nacionalidade e outros ensaios. Porto Alegre: Mercado Aberto, 1999.

BAUMAN, Zygmunt. Modernidade Líquida. Tradução Plínio Dentzien. - Rio de Janeiro: Jorge Zahar Ed., 2001.

CANDIDO, Antonio. Formação da literatura brasileira: Momentos decisivos. São Paulo: Martins, 1961. v.1.

CASTRO, Ronaldo Oliveira de. Pensamento social brasileiro e literatura contemporânea. In XIV Congresso Brasileiro de Sociologia. Rio de Janeiro, UERJ, julho de 2009.

LAUB, Michel. Diário da Queda. São Paulo: Companhia das Letras, 2011.

LIPOVETSKY, Gilles; SERROY, Jean. A Tela Global: mídias culturais e cinema na era hipermoderna. Tradução de Paulo Neves. Porto Alegre: Sulina, 2009.

MORICONI, Ítalo. Demarcando Terrenos, Alinhavando Notas. Para uma história da poesia recente no Brasil. In Revista Travessia, p. 17-31. Edição organizada por Rita de Cássia Barbosa. Editora da UFSC: 1992.

RICOEUR, Paul. A hermenêutica bíblica. Edições Loyola, São Paulo, 2006.

SIBILIA, Paula. O show do eu: a intimidade como espetáculo. Rio de Janeiro: Nova Fronteira, 2008.

SÜSSEKIND, Flora. Escalas \& Ventríloquos. Fonte: Mais! Folha de São Paulo: 23 de julho de 2000, p. 4-10

[Recebido em julho de 2012 e aceito para publicação em dezembro de 2012]

Searching for elements for a contemporary history of Brazilian literature: a view about Diário da Queda, from Michel Laub

Abstract: This paper aims to contribute for the understanding of the characteristics of contemporary brazilian literature by analyzing the novel "Diário da Queda", written by 
Michel Laub. "Diário da Queda" narrates the episode of the fall of a non-Jewish boy (João), age 13, who suffers an "accident", narrated years later by the man who was responsible for it (grandson of a Jewish survivor of Auschwitz). The implications of the "fall" of João drive the narrator-protagonist in a series of reflections about identity, memory and intolerance. Stating with this novel, we will outline a brief analysis of issues relating to its particular syntactic construction and the diary format. In addition, we discuss about the weakening of the narrator and the downsizing of the narrative. To reflect about the structural characteristics of the novel of Michel Laub, the analysis will be guided, mainly, buy these following authors: Moriconi (1992), Süssekind (2000), Bauman (2001) and Lipovestsky and Serroy (2009) and Castro (2009).

Keywords: Contemporary brazilian literature. Diário da Queda. History of literature.

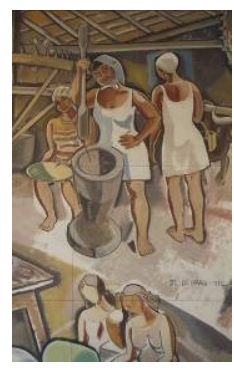

